\title{
Pharmaceutical service in the community pharmacy in Romania - present and future trends
}

\author{
Elena DINTE ${ }^{1,2}$, Sinziana RADULESCU ${ }^{3}$, Dana COLTOFEANU 3 , Mihaela POP 3 , \\ Nicoleta POPARLAN ${ }^{3}$, Cristina PAVEL ${ }^{3}$, Adina TORJE ${ }^{4}$ \\ ${ }^{1}$ Department of Pharmaceutical Technology and Biopharmaceutics, Faculty of Pharmacy, \\ "Iuliu Hatieganu" University of Medicine and Pharmacy, Cluj-Napoca, Romania \\ ${ }^{2}$ College of Pharmacists in Cluj County, Romania \\ ${ }^{3}$ Ethica Independent Pharmacies Association, Romania \\ ${ }^{4}$ Lea Vale Medical Group, Luton, United Kingdom
}

\begin{abstract}
Objectives. Highlighting the role of pharmacists in Romanian community pharmacies, in order to build rational approaches, and to establish the legal framework for the implementation of the pharmaceutical services. Analysis of activities carried out in community pharmacies in Romania and evaluation of the potential of pharmacists to provide quality pharmaceutical services.

Results. Most pharmacists in community pharmacies in Romania provide advice on medicines and other health services, without them being acknowledged or remunerated. The implementation and recognition of the pharmaceutical service is imperative and involves the establishment of unitary, quantifiable quality standards for each service, so as to benefit the patient, the medical staff and the health system.

Conclusions. Maximizing the intervention of community pharmacists in optimizing public health, by implementing pharmaceutical services, could reduce health care costs, and relieve medical staff, making it easier to manage current or crisis situations.
\end{abstract}

Keywords: pharmaceutical service, role of pharmacist, community pharmacy, COVID-19, pandemic

\section{INTRODUCTION}

The community pharmacies are, for many citizens, the first point of contact with the healthcare system, with pharmacists being the interface between doctor and patient, offering both advice on the correct use of medicines and advice on health education for the population. The community pharmacy is an important component of the health system, providing pharmaceutical care, an essential public service to the entire community they serve $(1,2)$. With a view to standardizing the approach to pharmaceutical care at European level, the Committee of Ministers of the Council of Europe adopted in March 2020 a resolution on "the implementation of pharmaceutical care for the benefit of patients and health services" (3), recommending that governments in Member States to 
take the necessary measures to promote and implement pharmaceutical care within national health systems, in accordance with the definitions and elements described in the appendix to the resolution. Pharmaceutical care is defined in that document as "the responsible provision of medicine therapy in order to achieve quantifiable results that improve the quality of life of patients" and "involves a process by which a pharmacist cooperates with a patient or other professionals in the design, implementation and monitoring of the therapeutic plan that will produce specific therapeutic results for the patient". In order to practically implement the concept of patient-centered pharmaceutical care, oriented pharmaceutical services are needed in this respect. Pharmaceutical practice varies considerably, depending on the state. The implementation and remuneration of pharmaceutical services in some states has shown positive effects both in terms of patient health and the associated economic benefits (4). In other states, the expertise of pharmacists is far from being recognized and capitalized on. Pharmaceutical services related to the basic activity of pharmaceutical practice, focused on the patient, in order to optimize therapy (medicine verification and monitoring, medicine therapy management, formulation of opinions in medicine selection) have already been implemented in many communities in the US, Europe, Canada. A pharmaceutical service funded in 2013 (5), Medicines Use Review (MUR), is implemented in the United Kingdom, in which accredited pharmacists systematically review the treatment of patients with complex medication, in order to identify non-adherence, administration errors, side effects, medicine interactions. Patients receiving asthma and other chronic conditions are especially targeted. Currently, the service can be provided by telephone or video consultation, where clinically appropriate. Similar services exist in other European countries. In Denmark, the Medicines Initiation Service has been included in the counseling guidelines for Danish community pharmacies since January 2016. The service is aimed at patients diagnosed with a new chronic condition or who have started a new treatment in the last six months and are remunerated by the government. Another Danish pharmaceutical service is the Adherence Increase Service for Patients with Chronic Disorders with Signs of Low Adherence, launched in April 2018, being given only to patients who after one year of treatment, show signs of low adherence (6). Since 2016 the pharmacies in Norway have been receiving compensation for training patients on the use of inhalers for the treatment of asthma. A similar compensation was introduced in 2018 for services related to antihypertensive, anticoagulant and lipid-lowering medicines. Pharmacies must provide two information meetings for each patient who begins to use these categories of medicines. Both schemes are publicly funded and free of charge for patients, with the aim of these information meetings being to improve compliance (7).

The large-scale crisis caused by the COVID-19 pandemic put pressure on health systems, which focused the authority's attention on the pharmacist's potential to provide extensive pharmaceutical services as well as other health services $(8,9)$. Thus, the International Pharmaceutical Federation (FIP) has published interim guidelines for pharmacists in the community pharmacy, and regulators in many developed countries, such as China, the United Kingdom, the United States, Australia and Canada, have adapted existing legislation, some provisions were made more flexible, or approved the development of additional activities in the Community pharmacy: extension of treatment recommendations in case of chronic diseases, initiation of treatment in case of acute diseases, extension of the recommendation for some medicines used in palliation (including opioids), advice on the use of sterile medicines, home delivery of medicines, testing-immunization, including for COVID-19, substitution of deficient medicines (in some cases, without a doctor's permission, to avoid discontinuation of treatment). These activities supported health systems, by ensuring the continuity of medicine therapy, maintaining the health of the population, compliance with restrictions and reducing the risk of contamination with the new coronavirus (10-12). The extension of the range of activities could be seen as an opportunity to change the paradigm of the role of the pharmacist in the Community pharmacy and an opportunity to expand the pharmacist's competences to be involved in prescribing medicines for certain diseases (13).

The paper aims to highlight the activities carried out by the community pharmacists in Romania and the specialized services they serve the population, without being recognized or remunerated, in the context in which there are concerns from the authorities to establish the legal framework for implementing pharmaceutical services in pharmacy as well as the approval of additional activities for the promotion of public health. 
LEGAL FRAME: LEGAL

REQUIREMENTS ABOUT

PHARMACEUTICAL SERVICES IMPLEMENTATION IN ROMANIA

Only recently, through changes that occur in Law no. $266 / 2008$ - Law of pharmacy, article $1^{1}$, the definition of pharmaceutical services were inserted in legislation: "an action or a set of actions carried out by a pharmacist with the right of practice, necessary to guarantee the pharmaceutical assistance of the population, integrated and continuous, in order to ensure the best response to the needs and health problems of the population as a whole and the patient individually". It is further stated that "pharmaceutical services include, but are not limited, to the release of medicines and the provision of information on their use, rational use of medicines, supervision of their administration, identification and avoidance of adverse drug effects, ensuring access to medication by preparing medicines, etc" $(14,15)$.

Even though previously the pharmaceutical services were not defined by national legislation, some of the services that took place in the community pharmacies were mentioned, such as: medicine dispensing, pharmaceutical preparation, fighting against selfmedication and excessive medicine-use, prevention (in cooperation with doctors), pharmacovigilance (Law no. 3/06.07.1978, articles 38 and 72) (16).

After communist revolution from 1989, the pharmacies that belonged to the state were privatized and became commercial societies (Government act no. 15/1991, on the establishment of pharmaceutical companies). The community pharmacies are established by taking over the assets and liabilities of the pharmaceutical offices, and the operation of the newly established companies went on for a period of time without any legal details regarding pharmaceutical services or any restriction on the establishment or operation of new pharmacies (17).

Between 1991 and 2001, pharmacies were established under Law no. 31/1990 - The law on commercial societies. There were rather provisions on medicines and their safety. Although the legislation of that period did not mention anything about pharmaceutical services, they were provided in all pharmacies rather as a result of the customs established by previous legislation. All pharmacies prepared pharmaceuticals and all pharmacists provided counseling (18).
In 2001, Order no. 626 of 11/09/2001 for the approval of the Rules on the establishment and authorization of pharmaceutical units and Requirements for their organization and functioning - introduced certain restrictions on the establishment of community pharmacies and expressly stated that the pharmacy issues pharmaceuticals, mentioning the service of the pharmaceutical compounding (19).

The current law - no. 266/2008 - was enforced in 2008. The law mentions the following pharmaceutical services (article 2): dispensing of medicines for both human and veterinary use; preparation of pharmaceuticals and other health products, providing information and counseling for the patients on the correct and rational use of medicines and maintaining their health; testing of biological parameters; administration of vaccines, only under the conditions required by Order of the Minister of Public Health. Community pharmacy participates in programs and campaigns to promote and protect the health of the population, in accordance with the professional skills of its staff (14).

As previously mentioned, the legal definition of the pharmaceutical services is a recent step, and at this moment our national legislation is acknowledging the fact that community pharmacies provide services. Yet, there is still to be specified by the legislation the list of the services that can be provided by the pharmacies, the way in which these services will be provided and paid. The authorities must detail all this until the end of 2021, and they had to elaborate and publish, together with the Pharmacists College of Romania, the detailed list of pharmaceutical services.

The most recent change of legislation regarding community pharmacies is dated from 1st of April 2021 and it reflex the intention of the authorities to involve pharmacies in the rapid testing activity for the detection of COVID-19 infection (Government Act no. 20/2021, amends article 2 paragraph (1) letter g) of the Pharmacy Law: "g) measurement of biological parameters, performance of tests for diagnostic purposes and administration of vaccines, under the conditions laid down by order of the Minister of Health". Thus, the personnel of the community pharmacies in Romania are permitted to perform tests in order to rapidly detect the infection with SARS-CoV-2. Even though this is not a pharmaceutical service, the authorities want this service performed in community pharmacies in order to facilitate the 
access of population to the tests and to rapidly detect potential infection. At this moment, the authorities are in the process of detailing the conditions under which these tests can be performed in community pharmacies (20).

\section{THE ACTIVITIES CARRIED OUT BY THE PHARMACISTS FROM THE COMMUNITY PHARMACIES IN ROMANIA}

Ensuring the accessibility of the public to medicines and health counseling is achieved by maintaining the operating schedule throughout the day, some pharmacies being open on public holidays, or $24 / 24$. During the quarantine period generated by the COVID-19 pandemic, pharmacists adapted the opening hours so as to provide the necessary time for the population to purchase their medicines, in many cases requiring a change in the staffing scheme in response to the restrictions imposed (21).

Ensuring the continuity of medicine care for the population, by permanently supplying the necessary medicines and counseling upon release. The role of the pharmacist in the health care of the population was strongly highlighted during the quarantine period established at the beginning of the pandemic, when pharmacists in community pharmacies ensured the continuity of medication by fractionally issuing prescriptions, given that there were discontinuities in medicines stocks. In order to limit the exposure time and repeated visits to both the doctor and the pharmacy, the prescription was sent to the pharmacy by electronic means, the patients were scheduled by telephone to pick up their medicines; also, in many cases, the counseling was also done by telephone. Understanding the need to deliver medicines constantly and safely, but also the desire to manage responsibly and ensure the traceability of the release process during the pandemic, pharmacists in community pharmacies in Cluj County have developed together with the Association of Independent Pharmacies in Romania, a procedure release of medicines for patients who cannot travel to the pharmacy (patients with acute conditions, including isolated / quarantined at home, pregnant women, patients with disabilities or chronic conditions who are at high risk of COVID-19 contamination). This was the basis for the development of a patient information guide, promoted by local authorities (22).
Ensuring patients access to personalized treatment through the pharmaceutical compounding activity - Through the preparation activity in the pharmacy, pharmacists provide therapy with personalized medicines, which are based on both formulas, recommended by the doctor and established formulas, formalized in pharmacopoeias. Some of them are reformulated industrial medicines, prescribed off-label or in pharmaceutical forms and doses adapted for use in children or the elderly. At the beginning of the pandemic, pharmacists in community pharmacies supported this activity and also distinguished themselves by preparing and providing the population with antiseptic solutions, as the shortage of commercial products for producers and distributors was an important problem (21).

Involvement in public health programs - Community pharmacists are permanently involved in health promotion projects, by disseminating information and advice on health education, being actively involved in promoting the vaccination campaign for COVID-19.

\section{THE BENEFITS OF THE RECOGNITION AND IMPLEMENTATION OF THE PHARMACEUTICAL SERVICE IN ROMANIA}

Studies have shown that the implementation of patient-centered pharmaceutical services in some states has benefited all parties involved. Analyzing the activity and competence of pharmacists in community pharmacies in Romania, the way they were involved in the management of the COVID-19 pandemic and the Romanian society's need for quality pharmaceutical care, were elaborated some possible benefits that can be brought by recognizing and implementing the pharmaceutical service (Table 1). From the patient's perspective, the most obvious benefits are improved management of chronic conditions (23).

From the doctor's point of view, he is relieved of time-consuming tasks, having the possibility to receive, through the pharmacist, concrete information related to possible side effects, interactions or contraindications regarding certain medicines. Thus, it is possible to increase the patient's adherence to treatment, reduce the frequency of doctor visits and increase the availability of other patients (24). 
Patient-centered pharmaceutical services bring multiple benefits to the health system as a whole. The pharmacist contributes decisively to the success of the medicine therapy recommended by the doctor, by the correct release of medicines and advice on how to administer them, to obtain maximum benefits and minimize the associated risks, which means reducing additional costs (need for a new specialist consultation, hospitalization in case of complications). There are enough arguments to demonstrate the important role of the community pharmacist in supporting the health system, having an ideal position for prevention, management of chronic diseases, timely identification of aggravations and referral of the patient to the doctor. The network of Community pharmacies also frequently serves as a convenient point for disseminating information on health problems and public health campaigns, respectively (25).

For the pharmacist practicing in the community pharmacy, the provision of patient-centered pharmaceutical services has the advantage of recovering and consolidating the status of health professional and increasing professional motivation by remunerating the provision of a clearly defined service, especially that the current model based on regressive scheme to medicines no longer corresponds to the realities and does not offer the possibility to pharmacies to offer salary increases.

\section{CONCLUSIONS}

Most pharmacists in community pharmacies in Romania currently provide counseling services for prescription or OTC medicines and provide valuable health information without the services being recognized or remunerated. Even if they have not been concretely defined, certain services have been expressly mentioned in the national legislation since 1978. It is necessary to draw up a list of pharmaceutical services and to establish clear, uniform, applicable, verifiable rules, which will bring an extended benefit to the healthcare system and all patients who come to the pharmacy.
TABLE 1. The benefits of the recognition and implementation of the pharmaceutical service in Romania

\begin{tabular}{|ll|}
\hline Beneficiary & \multicolumn{1}{c|}{ Benefit } \\
\hline Patient & $\begin{array}{l}\text { Optimizing the management of chronic } \\
\text { diseases } \\
\text { Reducing the risk of side effects } \\
\text { Increased adherence to treatment } \\
\text { Increasing the quality of life } \\
\text { Strengthening the pharmacist-patient } \\
\text { relationship by facilitating communication }\end{array}$ \\
\hline Pharmacist & $\begin{array}{l}\text { Valorization of professional knowledge } \\
\text { Strengthening the status of health professional } \\
\text { Increasing professional motivation }\end{array}$ \\
& $\begin{array}{l}\text { Optimizing the fulfillment of professional } \\
\text { objectives }\end{array}$ \\
\hline Doctor & $\begin{array}{l}\text { Reducing time-consuming tasks / increasing } \\
\text { other patients' access to consultation } \\
\text { Efficiency of therapy by reducing prescribing } \\
\text { errors and effective use of medicines } \\
\text { Increasing access to patient information } \\
\text { provided by the pharmacist (occurrence of side } \\
\text { effects, etc.) }\end{array}$ \\
\hline $\begin{array}{l}\text { Reducing healthcare costs by increasing } \\
\text { adherence to prescribed and settled treatment } \\
\text { Reducing the risk of progression of chronic } \\
\text { diseases } \\
\text { system } \\
\text { Reducing the risk of side effects from } \\
\text { treatment, which requires new therapy, or } \\
\text { even hospitalization } \\
\text { Optimizing the health level of the population } \\
\text { Streamlining public health campaigns by } \\
\text { co-opting pharmacists from community } \\
\text { pharmacies }\end{array}$ \\
\hline
\end{tabular}

On the other hand, for the successful realization of this desideratum, it is necessary to carefully analyze all the factors that can influence the quality of the service: availability and motivation of the human resource (pharmacist), continuous postgraduate training, financial reimbursement, analysis of circumstances and creation of legal framework to ensure the implementation and standardization of pharmaceutical practice, so that it is possible to quantify the quality of each activity. These conclusions could be a starting material for regulators, to lay the foundations for the recognition of the pharmaceutical service in Romania, so that the involvement of pharmacists in public health is maximized.

\section{REFERENCES}

1. Watson KE, Singleton JA, Tippett V, Nissen LM, Defining pharmacists' roles in disasters: a Delphi study. PloS One. 2019;14(12):e0227132.
2. Miller S, Patel N, Vadala T, Abrons J, Cerulli J. Defining the pharmacist role in the pandemic outbreak of novel H1N1 influenza. J Am Pharm Assoc. 2012;52(6):763-767. 
3. Council of Europe, Comitee of Ministers, Resolution CM/ Res(2020)3 on the implementation of pharmaceutical care for the benefit of patients and health services adopted by the Committee of Ministers on 11 March 2020. Available at: https://rm.coe. int/09000016809cdf26.

4. De Barra M, Scott CL, Scott N., Johnston M, de Bruin M, Nkansah N, Bond CM, Matheson Cl, Rackow P, Williams AJ, Watson MC. Pharmacist services for non-hospitalised patients. Cochrane Database of Systematic Reviews 2018;9.

5. Pharmaceutical Service Negotiating Committee (PSNC). Internet. Available at: http://psnc.org.uk/services-commissioning/ advanced-services/murs/.

6. Abrahamsen A, Burghle AH, Rossing C, Pharmaceutical care services available in Danish community pharmacies, International Journal of Clinical Pharmacy 2020;42:315-320.

7. WHO Collaborating Center for Pharmaceutical Pricing and Reimbursement Policies, PPRI Pharma Profile Norway 2018. Available at: https://ppri.goeg.at/sites/ppri.goeg.at/files/ inline-files/PPRI\%20Norway\%202018.pdf.

8. Strand MA, Bratberg J, Eukel H, Hardy M, Williams C, Community Pharmacists' Contributions to Disease Management During the COVID-19 Pandemic. Prev Chronic Dis. 2020;17:E69.

9. Ung COL, Community pharmacist in public health emergencies: quick to action against the coronavirus 2019-nCoV outbreak. Res Soc Adm Pharm. 2020;16(4):583-586.

10. Zheng S-Q, Yang L, Zhou P-X, Li H-B, Liu F, Zhao R-S. Recommendations and guidance for providing pharmaceutical care services during COVID-19 pandemic: A China perspective. Res Soc Adm Pharm. 2021;17:1819-1824.

11. International Pharmaceutical Federation (FIP Health Advisory). CORONAVIRUS SARS-CoV-2/ COVID-19 PANDEMIC: Information and interim guidelines for pharmacists and the pharmacy workforce. 2020 The Netherlands. Available at: https://www.fip.org/file/4729.

12. Cadogan CA, Hughes CM. On the frontline against COVID-19: Community pharmacists' contribution during a public health crisis. Res Soc Adm Pharm. 2021;17:2032-2035.

13. Nadeem MF, Samanta S, Mustafa F, Is the paradigm of community pharmacy practice expected to shift due to COVID-19? Res Soc Adm Pharm. 2021;17;2046-2048.

14. Pharmacy Law no. $266 / 2008$, Published in the Official Gazette, Part I no. 765 of November 13, 2008.

15. Law no. 243 of 09.11.2020 regarding the approval of the Government Act no. 4/2018 for the amendment and completion of the Pharmacy Law no. 266/2008, Published in the Official Gazette, Part I no. 1042 of June 11, 2020

Conflict of interest: none declared

Financial support: none declared
16. Law no. 3 of 06/07/1978 regarding Public Health, Published in the Official Gazette no. 54 of July 10, 1978.

17. Decision no. 15/1991 regarding pharmaceutical companies formation - joined stock company, Published in the Official Gazette, Part I no. 8 of January 16, 1991.

18. Company law no. 31/1990, Published in the Official Gazette, Part I no. 126 of January $17,1990$.

19. Order no. 626 of 11/09/2001, for the approval of the Rules regarding the formation and authorization of pharmaceutical units, as well as of the Conditions for their organization and functioning, Published in the Official Gazette, Part I no. 629 of October 8, 2001.

20. Government Act no. 20 / 2021- regarding the change and completion of Appendix no. 1 to the Order of the Minister of Health no. 1165 / 2020 for the approval of the maximum prices of human use medicines, valid in Romania, which can be used / marketed by marketing authorization of medicines holders or their representatives, wholesalers of medical services and medicines which are the subject of contractual relationships with the Ministry of Health, the health insurance companies and / or the Public Health of the county and of the municipality of Bucharest branches, included in the National List of prices for authorized medicines in Romania, generic and innovative reference prices, Published in the Official Gazette, Part I no. 62 of January 20, 2021.

21. Dinte E, Zehan T, Miclaus $G$, Sandor N, Vaida D, Vostinaru S, Implication of pharmacists in Cluj County in managing the COVID-19 pandemic. Ro J Pharm Pract. 2020;13(3):157-163.

22. College of Pharmacists in Cluj, News, "FarmaVoluntar" Project RO/ EN. Internet. Available at:http://www.cluj.colegfarm.ro/noutati/ Proiectul-quotFarmaVoluntarquot-ROEN.pdf.

23. Jódar-Sánchez F, Malet-Larrea A, Martín JJ, García-Mochón L, López Del Amo MP, Martínez-Martínez F, Gastelurrutia-Garralda MA, García-Cárdenas V, Sabater-Hernández D, Sáez-Benito L, Benrimoj SI. Cost-utility analysis of a medication review with follow-up service for older adults with polypharmacy in community pharmacies in Spain: the conSIGUE program. Pharmacoeconomics. 2015;33(6):599-610.

24. Elliott RA, Tanajewski L, Gkountouras G, Avery AJ, Barber N, Mehta R, Boyd MJ, Latif A, Chuter A, Justin Waring J. Cost Effectiveness of Support for People Starting a New Medication for a Long-Term Condition Through Community Pharmacies: An Economic Evaluation of the New Medicine Service (NMS) Compared with Normal Practice. Pharmacoeconomics. 2017;35(12):1237-1255.

25. Pharmaceutical Group of European Union, Pharmacy 2030: A vision For Community Pharmacy in Europe. Internet. Available at: https:// www.pgeu.eu/wp-content/uploads/2019/03/Pharmacy-2030_-AVision-for-Communit y-Pharmacy-in-Europe.pdf. 